\title{
Tumor Marker
}

National Cancer Institute

\section{Source}

National Cancer Institute. Tumor Marker. NCI Thesaurus. Code C17220.

A substance present in or produced by a tumor or by the host, that can be used for differentiating neoplastic from normal tissue based on measurements in body fluids, secretions, cells, and/or tissues. Markers are used in diagnosis, staging and prognosis of cancer, provide an estimation of tumor burden, and serve for monitoring effects of therapy, detecting recurrence, localization of tumors, and screening in general populations. 